\title{
CARNAP'S LOGICAL EMPIRICISM, VALUES, AND AMERICAN PRAGMATISM
}

\author{
Thomas Mormann
}

Abstract. Value judgments are meaningless. This thesis was one of the notorious tenets of Carnap's mature logical empiricism. Less well known is the fact that in the Aufbau values were considered as philosophically respectable entities that could be constituted from value experiences. About 1930, however, values were banished to the realm of meaningless metaphysics, and Carnap came to endorse a strict emotivism. The aim of this paper is to shed new light on the question why Carnap abandoned his originally positive attitude concerning values. It is argued that Carnap's non-cognitivist attitude was the symptom of a deep-rooted and never properly dissolved tension between his conflicting inclinations towards Neokantianism and Lebensphilosophie. In America Carnap's non-cognitivism became a major obstacle for a closer collaboration between logical empiricists and American pragmatists. Carnap's persisting adherence to the dualism of practical life and theoretical science was the ultimate reason why he could not accept Morris's and Kaplan's pragmatist theses that cognitivism might well are compatible with a logical and empiricist scientific philosophy.

0. Introduction . A major point on the agenda of history of philosophy of science is to un derstand how the European and the American version of logical empiricism were related. European logical empiricism is said to be not "intellectually continuous" with its American sucessor. According to Giere

"[T]he cause of this discontinuity was clearly not primarily intellectual. It was the forcible dislocation of many of the major participants from the culture of Germanspeaking Europe during the interwar years to the English-speaking world of North America beginning around 1933. It is with this fact that any future history of logical empiricism in North America must begin." (Giere 1996, 336)

Others blame WWII, the Cold war, or McCarthyism to be responsible for the transformation of European logical empiricism, conceived as a "progressive" and "enlightenment-oriented" 
scientific philosophy, into the "neutral“ philosophy of science known as the "received view". In this paper l'll argue that "external factors" do not suffice to explain the above-mentioned transformation. There was indeed a "discontinuity" in the evolution of logical empiricism, but it took place already in Europe before the logical empiricists emigrated to the New world. This European discontinuity affected the development of logical empiricism in America and paved the road to the "neutral" philosophy of science as which logical empiricism ended in the seventies of the last century.

The first main thesis of this paper is that the European discontinuity was caused by an inherent tension between two opposing background factors that determined much of Germanspeaking European philosophy in the early decades of the $20^{\text {th }}$ century, namely the antagonism between Neokantian currents of "scientific" philosophy" and irrationalist Lebensphilosophie. Carnap put forward two different proposals to solve this tension:

(1) The first proposal was the Aufbau's "comprehensive scientific philosophy" (CSP). According to it the constitution theory of the Aufbau was the core of scientific philosophy. Science, philosophy, and progressive movements in education, politics and the arts were to collaborate to bring about a just and enligthened socialist society (cf. Aufbau, Introduction, Manifesto). Values were considered as philosophically respectable entities that any good constitution system had to comprise.

(2) The second proposal was a more "restrictive scientific philosophy" (RSP) first outlined Philosophy and Logical Syntax (1935). According to (RSP), philosophy was the syntactical theory of the language of science. Consequently, (RSP) had not political or societal commitments whatsoever. In Logical Foundations of the Unity of Science (Carnap 1938) (RSP) was even denied to be philosophy at all.

The shift from (CSP) to (RSP) began around 1930 and amounted to a radical reconception of logical empiricism. The politically engaged version of logical empiricism was theoretically given up by the replacement of (CSP) by (RSP). This change, I hasten to add, did not mean that Carnap's political and societal engagement vanished around 1930. It lived on at an emotional level, so to speak, but it was no longer backed by theoretical considerations. The theoretical realm of scientific philosophy and the practical realm of social and political commitment became strictly separated. This separation of the theoretical and the practical paved the road to the transformation of logical empiricism into the neutral philosophy of science that became known as the "received view".

The most visible symptom of the substitution of (CSP) by (RSP) was a strict anti-cognitivist stance of the latter. But anti-cognitivism was only the tip of the iceberg of a more 
profound difference between the two currents, as became evident when European logical empiricists and American pragmatists came into closer contact from the thirties onwards. While the (RSP)-version of logical empiricism endorsed a Cartesian separation between the practical and the theoretical, American pragmatists were opposed to any kind of Cartesian dichotomies; in particular, they did not draw a neat line between facts and values.

The second main thesis of this paper contends that the difference between European logical empiricism and its American successor was prefigured by the difference between (CSP) and (RSP): (RSP) laid the theoretical foundations for what was to become "philosophy of science" in the American sense. The "transformation" that European logical empiricism underwent should therefore not solely be explained by external causes such as the forcible emigration or the cold war etc. Rather, there were internal reasons as well that explain why the logical empiricists undertook their journey to the "icy slopes of logic" (cf. Neurath 1929, 339) and lost contact with the lowlands of science and common sense.

As will be shown in the sequel, these internal reasons are particularly important to understand why the sustained efforts of the American pragmatists failed to forge a synthesis between the two currents.

1. Values in the Aufbau. To set the stage, recall that the world of the Aufbau was a four layered world consisting of the four layers of autopsychical, physical, heteropsychical, and cultural objects (cf. Aufbau, Summary, pp. 241/242). Among the cultural objects we find values ( $\S 152$ ). Although they belonged to the fourth constitutional level of the system their constitution was based on items belonging to the lowest level of the constitutional system, to wit, elementary experiences of a special kind:

"The construction of values from certain experiences, namely Werterlebnisse, is in many ways analogous to the construction of physical things from "perceptual experiences" ... For the construction of ethical values, for example, we must consider (among others) experiences of conscience, experiences of duty or of responsibility, etc. For aesthetic values, we take into account experiences of (aestetic) pleasure or other attitudes in the appreciation of art, experiences of artistic creation, etc. The particular nature of the value experiences of the different value types is investigated by the phenomenology of values... " (Aufbau, $\S 152)$.

When Carnap wrote the Aufbau in the early 20s he was strongly influenced by Southwest neokantianism, in particular Rickert. Indeed, there are important similarities between Rickert's System der Philosophie (Rickert 1921) and the Aufbau (cf. Mormann 2006). The essential point for the following is that for Carnap (then following Rickert) values did belong to the ken of constitution. Values could be constituted in the constitutional system, and it was 
essential for the constitution system that this was the case. Indeed, Carnap was at pains to point out that values could be constituted in all kinds of constitution systems (Aufbau § 59). The world of the Aufbau was a world in which values played an indispensable role.

On the other hand, Carnap was deeply impressed by the philosophical current characterized vaguely as "philosophy of life“ (Lebensphilosophie), in particular by Nietzsche. For Carnap, Lebensphilosophie was not so much a philosophical doctrine having an argumentative content, but rather a neo-romantic attitude that took a person's "life-feeling“ (Lebensgefüh/ as the ultimate legitimate guide for what he considered as appropriate for living his life according to his preferences and inclinations. No philosophical doctrine should restrict the individual's autonomy by reglementing his Lebensgefühle. Emphasizing the autonomy of Leben and its difference to reason led Carnap to a strict "Cartesian" dualism, for which the practical realm of of life and the theoretical realm of science were neatly separated.

This attitude based on Lebensgefühle was not easily compatible with Carnap's scientific and philosophical interests. This was true all the more, since the Neokantian philosophy aimed at a global science-oriented Weltanschauung that comprised all aspects of reality. In the early and middle twenties Carnap was very impressed by the systematic Neokantian way of philosophizing that intended to comprehend all aspects of society and culture. The Aufbau may be conceived as a young philosopher's ambitious project to provide a philosophical system in the spirit of Neokantianism, but avoiding its logical and scientific weaknesses and limitations. This thorough modernization of the Neokantian program, however, should not obscure the fact that the systematic spirit of Rickert and Carnap's endeavors were rather similar.

Seen from the perspective of Lebensphilosophie the Aufbau was overstretching the ken of reason and rationality. In particular, it threatened the autonomy of Leben as the domain of values. Indeed, in the Aufbau for every kind of value (ethical, esthetical, economic, and biological) there was a specific phenomenology (cf. Aufbau §152). A partisan of the autonomy of Lebensgefühle would have felt unduly regimented by the resulting ethics, esthetics, and other normative theories. In any case, about 1929/30 Carnap came to the conviction that the program of (CSP), as sketched in the Aufbau and still maintained in the Manifesto, was not feasible. According to the new program of (RSP) philosophy was to be pursued as the theory of the syntax of scientific language (cf. Carnap 1934,1935). In this frame there was no room for value statements, psychological, sociological, or historical considerations about science.

The shift from (CSP) to (RSP) did not mean that the members of the Vienna circle suddenly lost interest in "value-laden" topics such as bringing about a just socialist society, or assessing the on-going developments in politics or art. Quite the contrary, in the early 
thirties Carnap's political commitment in the Vienna Circle, the Ernst Mach Society, and similar institutions reached its peak. But his commitment was based on his Lebensgefüh/ and not related to scientific philosophy in the sense of (RSP). With respect to matters of $\mathrm{va}$ lues, this separation led to a radical emotivism for which values belonged to the noncognitive domain of Lebensgefühl. The resulting dualism was to become the main reason for the controversies between logical empiricists and American pragmatists.

2. The Expulsion of Values from the Constitutional Paradise. The expulsion of values from the realm of respectable philosophical entities began shortly after the Aufbau had been published in 1928. In the Manifesto (1929) the constitution theory of the Aufbau was still considered as the theoretical background of unified science (ibidem, p. 307). Although the Manifesto considered metaphysics and theology as "debris" (p. 317), nothing was said against values and value statements. The first attack on values was put forward in a lecture Carnap delivered in October 1929 at the Bauhaus in Dessau. In this lecture he argued for a purely instrumental role of science and advocated an irreducible plurality of values. To his opinion, "valuation (Wertung) is not the cognition of a fact but a personal attitude." (Carnap 1929, RC-110-0749-2). Hence, facts and values had to be neatly separated. The choice of a value was considered as a matter of one's personal Lebensgefühl.

The definite dismissal of values as objects of scientific philosophy took place in Overcoming $(1931 / 32)$. Usually this paper is considered as a somewhat naive antimetaphysical pamphlet best known for the violent attack on Heidegger's "philososphy of the Nothing". Actually Overcoming is also a document in which Carnap reported his private overcoming of metaphysics, in particular value theory. Thereby an important part of the Aufbau's constitutional program was abandoned. Overcoming marked the separation of his philosophy from its Neokantian origins and announced the beginning of the genuine logical empiricist period of his philosophizing. This did not mean, however, that the tension between Leben and Geist (reason) had disappeared. As will be shown in the next section it was to resurface in his dispute with American pragmatists on the cognitive status of value judgments. From Overcoming onwards, for Carnap the world that science dealt with was a world of facts without values.

The choice of basic values was a matter of "character" (cf. Carnap 1929, and Carnap 1963, 1009). This meant, for instance, that there was no moral difference between a "consequent capitalism" founded on the value of individual enrichment and "socialism" based on the value of solidarity. The choice of basic values dropped out of the rational discourse. There were no 
reasons for a choosing one basic value or another. It was a matter of taste or "character". This entailed that value statements were cognitively meaningless. Values were relegated to irrational Leben. They became impulses and instincts that might be studied by psychology, biology or other sciences, but that no longer belonged to the sphere of reasons. The resulting picture of the world was most clearly presented in his semi-popular lectures Philosophy and Logical Syntax (1935). Distinguishing between the two basic functions of language, namely, expression and representation, he proposed the following scheme (Ibidem, 32):

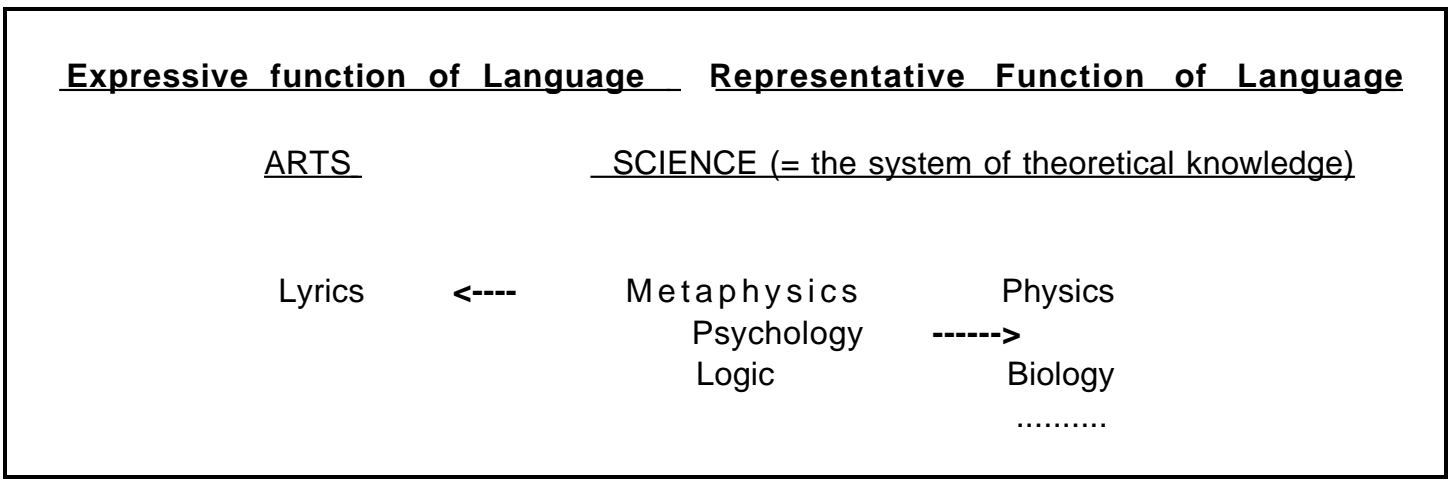

It never occurred to Carnap that science might involve theoretical and practical knowledge. Consequently, his system did not provide a place for practical knowledge. This scheme of the relations between philosophy, science, and arts remained essentially intact when Carnap had immigrated to America. Of course, the conception of philosophy of science as syntax of scientific language was replaced by one that took into account also semantical and "pragmatic" aspects of scientific language. But semantics remained as theoretical as syntax, and, as Morris rightly remarked, Carnap's "pragmatics of scientific language" was a far cry from pragmatism and remained rather underdeveloped.

Summarizing one may say that already in Europe Carnap had covered a long way towards the "icy slopes of logic" (Manifesto, 339), which recently were claimed to be characteristic for "logical empiricism in the age of Cold War" (cf. Reisch 2005). From the mid-thirties onwards Carnap's logical empiricism was no longer engaged theoretically in practical issues of society and politics. ${ }^{1}$ This fact was masked by his ongoing political commitment. This, however, did not take place in the theoretical framework of (RSP) but was motivated by his Lebensgefüh/ marked by the cultural and political context of "Red Vienna".

\footnotetext{
1 Uebel's recently proposed to characterize the theoretical content of the left Vienna circle's approach in terms of an "anticorrespondentist anti-metaphysics“ (Uebel 2004, 272). With Morris one may wonder if this stance can be cast in the framework of pure logical analysis of language.
} 


\section{Pragmatist Criticisms of logical empiricist Non-cognitivism. By Overcoming Carnap}

might have hoped to have brought to an end the discussion on values among scientific philosophers once and for all. This, however, was not the case. When he came to the U.S., the problem of values was to become a major topic in his disputes with his pragmatist allies. Even worse, the pragmatists did not confine the discussion to the (RSP) version of logical empiricism but exhumed the value-friendly account of the Aufbau. For instance, already in 1936 Lewis had spotted the ominous $\S 152$ of the Aufbau in which Carnap had sketched the constitution of values on the base of value experiences (cf. Lewis 1936, p. 153). For Lewis, the analogy there drawn between perceptual experiences and value experiences was just"obvious". But he confessed that he was unable "to interpret this passage ( $\S 152$ ) in a manner consonant with the general position of the Vienna Circle with respect to the normative ...." (Ibidem, 152). As it seems, Carnap felt unable too, since he never responded to Lewis's remark.

In the early forties Dewey published $A$ Theory of Valuation in the Encyclopedia of Unified Science edited by Neurath, Carnap, and Morris. For Dewey the meaningfulness of value statements belonged to the essence of pragmatism, and he and the logical empiricists were well aware that their positions were hardly compatible. Nevertheless, apparently for tactical reasons both groups were ready to cooperate (cf. Reisch 2005). Carnap even swallowed the following remark in which Dewey came quite close to the bottom of the logical empiricists's insistence on a strictly emotivist account of ethics:

"The hard-and-fast line which is supposed by some to exist between "emotive" and "scientific" language is a reflex of the gap that exists between the intellectual and the emotional in human relations and activities. ... The practical problem that has to be faced is the establishment of cultural conditions that will support the kinds of behavior in which emotion and ideas, desires and appraisals, are integrated (Dewey 1970(1944), 444 - 445).

It is hard to say whether Dewey knew much about the role Leben and Lebensphilosophie had for Carnap's fundamental philosophical convictions. In any case he had spotted clear-sightedly the crucial weakness of Carnap's position that unduly restricted the domain of rationality to the theoretical.

Lewis and Dewey were not the only pragmatists who attacked the logical empiricist noncognitivim. In the same vein as Lewis, still in 1963 Morris pointed out that Carnap had endorsed in the Aufbau a constitution of values quite in line with Lewis's pragmatist account (cf. Morris 1963). Again, Carnap did not respond to Morris's challenge.

Independently of the constitution theory Morris saw still another possibility for a rapprochement between Carnap's logical empiricism and pragmatism in which value judgments would be important, namely, the realm of rules and proposals that had become central to Carnap's 
philosophy. This option referred to (CSP) and (RSP) alike. As Morris pointed out, Carnap often went beyond a mere logical analysis and reconstruction of scientific knowledge, making proposals of how science, society and life might be organized:

"In the Logische Aufbau Carnap writes that life has many dimensions other than science, and the restriction of the term "knowledge" to science is helpful to the friendly relation between the various spheres of life, for the admission of complete heterogeneity would lessen the strife between them (pp. 257/8) This may or may not be the case, but the statement is certainly more than a logical analysis of science. It contains a recommendation or proposal, made in terms of a theory of the relation of science to other human activities." (Morris 1963, 97)

Indeed, making "proposals" or "recommendations" was to become one of the most important characteristics of Carnap's mature style of philosophizing. Already in the first paper he published in America, On the Character of Philosophic Problems (Carnap 1934) he was at pains to bar possible misunderstandings concerning the (RSP) conception of philosophy of science as logic or syntax of science, pointing out that a philosophical theorem, formulated as a proposition of syntax, could be read in two different ways, namely, as an assertion, or, most often more appropriate, as a proposal (cf. Carnap 1934). In the following decades he emphasised the proposal character of philosophy again and again (cf. Testability and Meaning (1936/37) and Empiricism, Semantics, and Ontology (1950)). From a pragmatist point of view "making proposals" is a value-laden activity. Proposals are made for realizing certain goals that are assessed to be valuable (cf. Lewis 1971). In (Carnap 1950) these pragmatic questions were characterized as "external questions" and contrasted with "internal questions" that could be decided by empirical and/or logical methods. Carnap denied that external questions were a legitimate topic of rational deliberations. Rather, he believed in a kind of Darwinian conceptual evolution ${ }^{2}$ in which only the fittest would survive:

"The acceptance or rejection of linguistic forms ... will finally be decided by their efficiency as instruments, the ratio of the results achieved to the amount and complexity of the efforts required. ... Let us grant to those who work in any special field of investigation the freedom to use any form of expression ...; the work in this field will sooner or later lead to the elimination of those forms which have no useful function." Carnap (1950, 221)

Evidently, this process of elimination is determined by a complex net of preferences, evaluations and practical assessments. Nevertheless, according to (RSP) this fact was of no concern to philosophy. Rather, the only task of philosophy, as a theoretical activity, was to

\footnotetext{
${ }^{2}$ In other words, Carnap conceived the confrontation between competing linguistic forms as an example of "the struggle for life". An analogous idea can be found already in the Lebensphilosophie of Dilthey who applied this Darwinian concept to the struggle of Weltanschauungen: "Those Weltanschauungen that lead to useful conceptions of life and foster its understanding, maintain themselves and supersede the lesser ones" (Dilthey VIII, 85).
} 
propose frameworks that were to be used, and eventually be approved or rejected by their practionners. From a pragmatist perspective this is but a poor caricature of what is going on in science. It made sense only for someone like Carnap, who assumed from the outset a strict separation between the theoretical and the practical: philosophers on the theoretical side design linguistic or ontological forms, and scientists, on the practical side test them. This division of labour is not very convincing.

Let us finally consider Abraham Kaplan's attempt to make a breach in Carnap's strict noncognitivism. Kaplan, belonging to a younger generation of American pragmatists did not refer to Carnap's "European" Aufbau. Instead, he intended to overcome Carnap's non-cognitivism from a purely American perspective. His main objection was that non-cognitivism was based on an implausible and question-begging fact-value dualism:

"The basic error in the fact-value dualism lies in the supposition that sooner or later every value judgment must come to rest upon an absolute end, one which is valued unconditionally, without ifs, ands, or buts. Factual considerations relate only to such conditions, and when these have been let go, we are left afloat in a sea of subjectivity. That absolute values are groundless does indeed imply that rationality precludes them; but the conclusion that they underlie all value judgments, which therefore cannot be objective, only begs the question." (Kaplan 1964, p. 394)

Kaplan's position directly contradicted Carnap's Cartesian dualism according to which in every value judgment one could neatly distinguish between means and ends such that eventually a purely optative component could be singled out that had no cognitive meaning whatsoever. As Carnap put it: "In contrast to Kaplan's conception, I assert [that] there are pure optatives. Cognitivism may be defined as the denial of this thesis." (Carnap 1963, 1001). According to him, a typical pure optative was a sentence like "Let us take road a rather than b." Such a sentence, Carnap insisted, had no cognitive meaning since no factual sentence was logically implied by it. Hence, according to the logical empiricist meaning criteria as laid down, for instance, in Overcoming thirty years earlier, a pure optative was cognitively meaningless. It should be noted that Carnap's argumentation was based on a very strict meaning criterion: only classical deductive logic was could bestow cognitive meaning to a proposition $p$, the meaning of $p$ defined as the totality of propositions that can be deduced from it. Inductive logic or any other kind of logic dealing with only plausible and less than perfect arguments cannot convey cognitive meaning to a proposition. This not only flew into the face of any pragmatist account, but also was hardly plausible in the light of Carnap's tolerance principle. 
Carnap's insistence on the existence of pure optatives is explained by the fact that pure optatives witnessed the autonomy of the domain of Lebensgefüh/thereby supporting one of his basic philosophical tenets.

5. Scientific Philosophy versus Philosophy of Science. The characteristic predicament of Carnap's philosophical stance, namely the tension between Lebensphilosophie and scienceoriented Neokantianism never let him seriously consider seriously proposal to strive for a synthesis of logical empiricism and pragmatism (cf. Morris 1937). After he had given up (CSP) and subscribed to (RSP) in the early 30s for him the separation between the sphere of reason and the sphere of life was not negotiable anymore.

Now European Neokantianism and American pragmatism both were aiming at a comprehensive philosophical understanding of the world in all its aspects subscribing to an ample notion of rationality that had a place for facts and values. In contrast, (RSP) opted for a purely formal concept of rationality that excluded values from the sphere of reason. Thus, the relation between (RSP) and Neokantianism on the hand, and between (RSP) and Pragmatism on the other were in some sense analogous. Hence, for Carnap was more at stake than what met the eyes of American pragmatists. Endorsing the pragmatist position would have meant for him a kind of return to his Neokantian past that he had overcome more than thirties years ago. Once again he would have become a follower of a comprehensive system of scientific philosophy similar in many aspects to (CSP). This he could not do, since it would have meant "to blur the difference between "attitude and theory" which was "of decisive importance" for his philosophy in general, as he had already pointed out in Overcoming ( $p$. 79).

Thus, for Carnap emotivism was not a surface phenomenon. Rather, it was a symptom of a deeply entrenched Cartesian predicament caused by the tension between Leben and Geist typical for much of Central European philosophy of the early 20th century. It served as the signpost for the conviction that philosophy and science were essentially theoretical endeavors that should be kept separated from the unfathomable feelings and practices of life. This view was imcompatible with pragmatism. Such a verdict squarely contradicts Richardson's recent diagnosis, who proposed to discuss the issues of cognitivism and emotivism as a merely rhetorical difference between the logical empiricist and the pragmatist program. More precisely, according to him the rhetoric of logical empiricism was demarcationist: "the point was to demarcate the proper role of science and to find the scientifically acceptable replacement for a core of scientific philosophy" ... [. On the other 
hand, Dewey's characteristic rhetoric is said to be "imperialist": the point is to bring scientific rigor into all areas of philosophical concern..." (Richardson 2002, S45).

In this paper I have argued that the dispute about the cognitive status of value judgments should be taken as a symptom of a more profound epistemological difference, namely, the difference between a Cartesian approach of (RSP) that strictly separated the theoretical and the practical, and an anti-Cartesian (pragmatist) approach that denied that such a separation made sense. External causes aggravated this dualism but they only brought to the fore what had been laid down theoretically already around1930 when the Neokantian (CSP) version of logical empiricism was replaced by the (RSP) version. Thus, although there can be no doubt that external factors contributed to the evolution of the American brand of logical empiricism, this development was also marked by internal factors of European provenance that should not be neglected if one wants to get the picture right.

References:

Carnap, R., 1928(1967), The Logical Construction of the World, Berkeley and Los Angeles, University of California Press. (Aufbau)

Carnap, R., 1928, Scheinprobleme in der Philosophie, Berlin, Weltkreis Verlag.

Carnap, R., 1929, Wissenschaft und Leben (Unveröffentlichte Notizen für einen Vortrag in Dessau, 15.10.1929, RC-110 - 07 - 49 - 1, Archives for Scientific Philosophy, University of Pittsburgh, Hillman Library.

Carnap, R., 1932, Überwindung der Metaphysik durch logische Analyse der Sprache, Erkenntnis 2, 60-80. (Overcoming)

Carnap, R., 1934, Theoretische Fragen und praktische Entscheidungen, Natur und Geist 2 , $257-260$.

Carnap, R., 1934, The Character of Philosophical Problems, Philosophy of Science 1, 5 19.

Carnap, R., 1935, Philosophy and Logical Syntax, London, Kegan, Trench and Trubner.

Carnap, R., 1938, Logical Foundations of the Unity of Science, in International Encyclopedia of Unified Science, vol. 1, no. I, Chicago, Chicago University Press.

Carnap, R., 1950, Empiricism, Semantics, and Ontology, Revue International de Philosophie 4, $20-40$.

Carnap, R., 1963a, Intellectual Autobiography, in P.A. Schilpp, The Philosophy of Rudolf Carnap (ed.), La Salle and Chicago, Open Court, 3 - 84.

Carnap, R., 1963b, Abraham Kaplan on Value Judgment, in P.A. Schilpp, The Philosophy of Rudolf Carnap (ed.), La Salle and Chicago, Open Court, 999 - 1013. 
Dewey, J., 1944(1970), A Theory of Valuation, in Foundations of the Unity of Science, Chicago, University of Chicago Press, 379 - 447.

Giere, R., 1996, From Wissenschaftliche Philosophie to Philosophy of Science, in R.N. Giere and A.W. Richardson (eds.), Origins of Logical Empiricism, Minnesota Studies in the Philosophy of Science XVI, 335 - 354.

Kaplan, A., 1963, Logical Empiricism and Value Judgments, in P. A. Schilpp (ed.), The Philosophy of Rudolf Carnap, La Salle and Chicago, Open Court, 827 - 856.

Kaplan, A., 1964, The Conduct of Inquiry. Methodology for Behavioral Science, New York, Chandler.

Lewis, C. I., 1946. An Analysis of Knowledge and Valuation, The Paul Carus Lectures, La Salle and Chicago, Open Court.

Lewis, C.I., 1970, Collected Papers of Clarence Irving Lewis. Edited by John D. Goheen and John L. Mothershead, Jr., Stanford, Stanford University Press.

Mormann, T. 2006, Werte bei Carnap, Zeitschrift für philosophische Forschung, to appear.

Morris, C. W., 1937, Logical Positivism, Pragmatism, and Scientific Empiricism, Actualités scientifiques et industrielles 449, Exposés de Philosophie Scientifique, Paris, Hermann. Morris, C., 1963, Pragmatism and Logical Empiricism, in P.A.Schilpp, The Philosophy of Rudolf Carnap, La Salle and Chicago, Open Court, 87 - 98.

Neurath, O., 1929, Wissenschaftliche Weltauffassung. Der Wiener Kreis, in S. Sarkar (ed.) Basic Works of Logical Empiricism,volume I, The Emergence of Logical Empiricism. From 1900 to the Vienna Circle, New York and London, Garland Publishers, 321 - 340. (Manifesto).

Reisch, G., 2005, How the Cold War Changed Philosophy of Science in America. To the Icy Slopes of Logic, Cambridge, Cambridge University Press.

Richardson, A.W., 1996, From Epistemology to the Logic of Science: Carnap's Philosophy of Empirical Knowledge in the 1930s, in R.N. Giere and A.W. Richardson (eds.), Origins of Logical Empiricism, Minnesota Studies in the Philosophy of Science XVI, 309 - 334.

Richardson, A. W., 2002, Engineering Philosophy of Science: American Pragmatism and Logical Empiricism in the 1930s, Philosophy of Science 69 (3) (Supplement), S36 - S47.

Uebel, T., 2004, Carnap, the Left Vienna Circle, and Neopositivist Ant-Metaphysics, in S. Awodey and C. Klein (eds.), Carnap Brought Home. The View from Jena, La Salle and Chicago, Open Court, 247 - 277. 